\title{
Processos Históricos, Análise Contemporânea: Documentação de Desenhos na Parede do Consistório da Capela do Carmo em Ouro Preto-MG, no Brasil
}

\author{
Historical Processes, Contemporary Analysis: Documentation Drawings on the Wall of the Consistory of \\ the Carmelite Chapel in Ouro Preto, Minas Gerais, Brazil
}

\author{
Rodrigo Luiz Minot Gutierrez \\ Universidade de São Paulo \\ Universidade Federal de Ouro Preto \\ Universidade de Uberaba, Brasil. \\ rodrigominot@hotmail.com
}

\begin{abstract}
Given the lack of studies on the design (or Risco) in the wall of the Church of Carmo de Ouro Preto, and references to it were found in the documents of 1789 , saw the need to develop a detailed study of the same, which can be described in the following steps: photographic documentation, drawings and descriptive observation, mapping and analysis of photographs, scanning and vectorization, interpretation and analysis. It is about the process of reflection on history, based on the use of Digital Technologies that this article discusses.
\end{abstract}

Keywords: Risco; Carmo; Barroque; History of the project.

\section{Introdução}

Na cidade brasileira de Ouro Preto, existe a "Capela da Ordem Terceira do Carmo". Localizada próximo à Praça Tiradentes, no alto do Morro de Santa Quitéria. Nessa capela é possível observar, em uma das paredes do Consistório, uma sequência de desenhos em grande escala, aparentemente representando um retábulo, com volutas, colunas, altar e detalhes típicos da talha "Barroca" de Minas Gerais. Esses desenhos fazem parte da construção do imaginário do "Barroco Mineiro", incluindo a construção do Mito do herói mulato Aleijadinho. Podendo ilustrar parte do universo das Representações da Arquitetura, usuais no século XVIII, no império português.

Após pesquisar os arquivos da "Irmande do Carmo", Lopes (1942), publica pelo SPHAN (Serviço do Patrimônio Histórico e Artístico Nacional) a "História da Construção da Igreja do Carmo de Ouro Preto", citando trechos de documentos de 1789 que mencionam um Risco (desenho ou projeto, conforme dicionário de Rafael Bluteau) feito na parede pelo mestre João Gomes para a definição de um dos altares colaterais, entalhado por Francisco Antônio Lisboa e com douramento de Manuel da Costa Ataíde (Lopes,1942).

O estudo desse desenho existente na parede e dos documentos da irmandade do Carmo faz parte de Trabalho de Conclusão da Especialização em "Cultura e Arte Barroca", pela Universidade Federal de Ouro Preto (UFOP), e pesquisa de Mestrado que está sendo desenvolvida no Programa de Pós-Graduação (PPG) da Faculdade de Arquitetura e Urbanismo (FAU) da Universidade de São Paulo (USP), na cidade de São Paulo, no Brasil. Sendo inclusive, parte integrante das pesquisas sobre as "Representações" desenvolvidas no "NA WEB" - Núcleo de Apoio à Pesquisa em Ambientes Colaborativos.

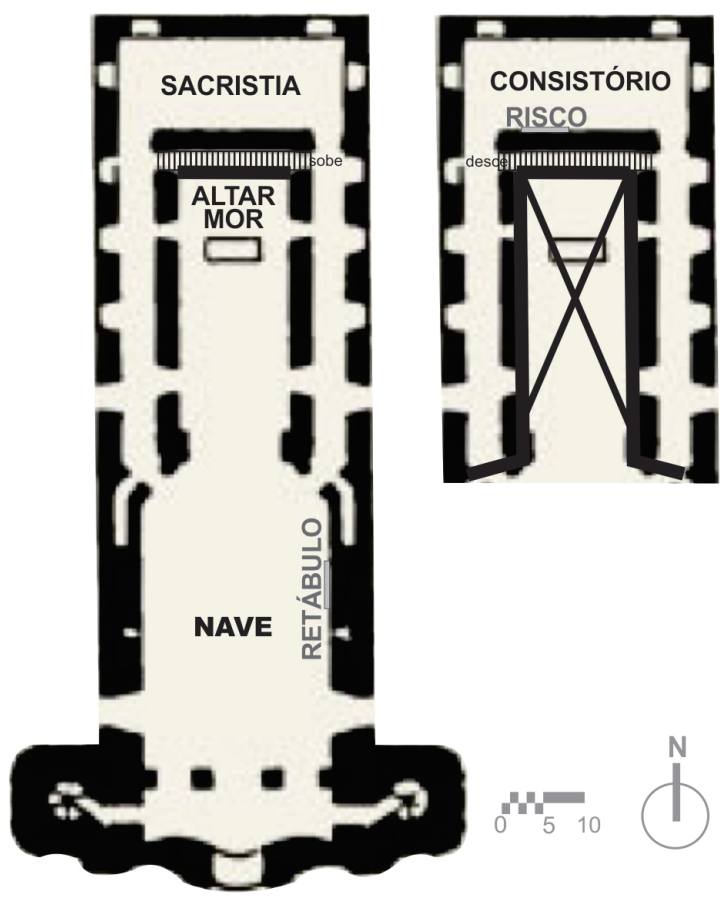

Figura 1: Planta esquemática da Igreja da Irmandade do Carmo de Ouro Preto (Bury, 2006, p.133) com intervenção indicando a localização do Risco no Consistório e do Retábulo Colateral para o qual João Gomes deve ter feito o Risco na parede durante uma Mesa da Irmandade. 

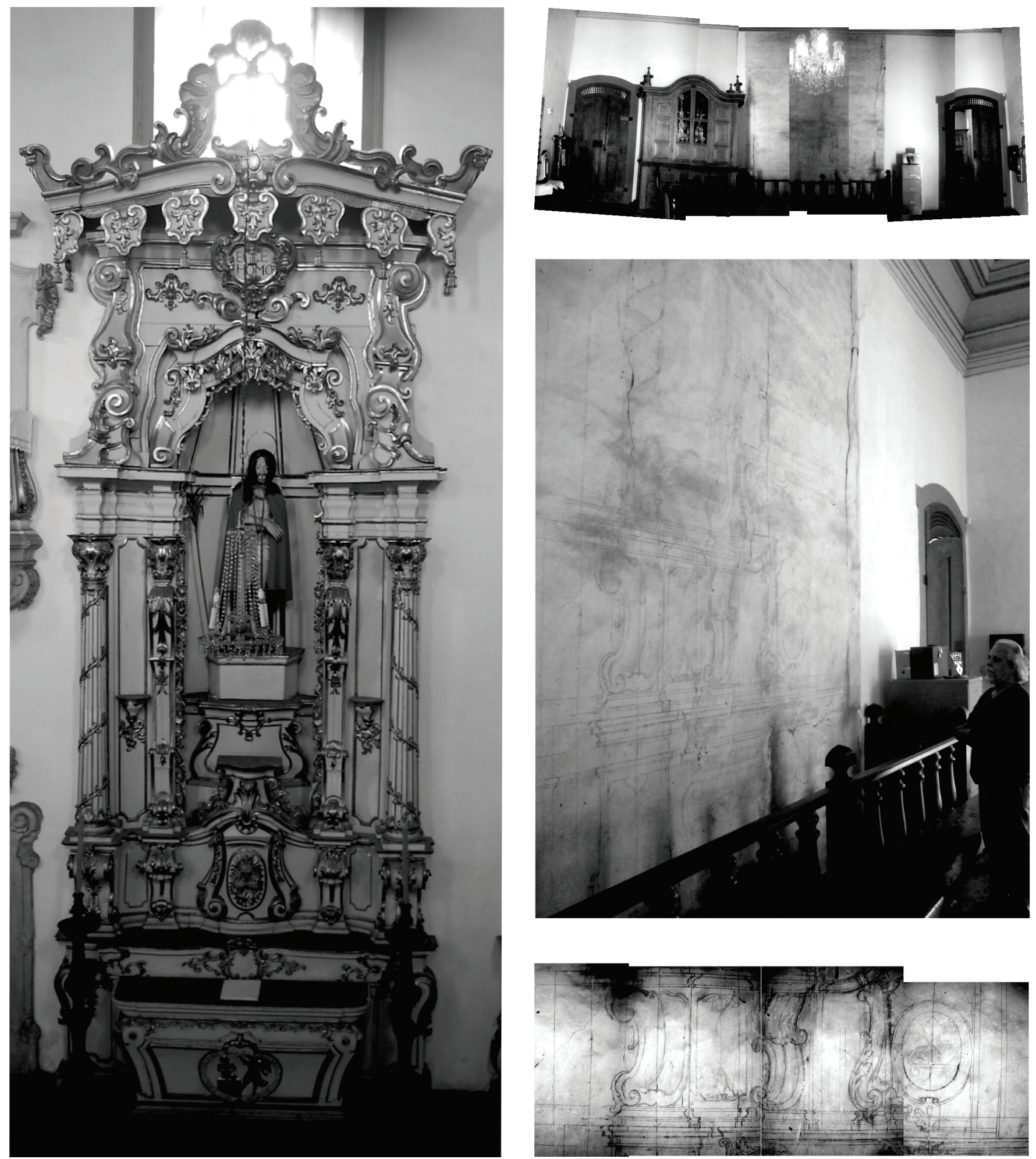

Figura 2: O desenho na parede do consistório, imagens à direita (Vista geral, Desenho e detalhe do Desenho - fotos do autor), de acordo com os documentos da irmandade é vinculado à fábrica do altar colateral central (Lopes, 1942) que está no lado do Evangelho, à direita da Nave para quem entra na igreja, imagem maior à esquerda (detalhe de foto de Lia Sipaúba), dedicado a "Jesus no Pretório e Nossa Senhora da Piedade" (NEVES, 2012). Entalhado por Francisco Antônio Lisboa e douramento de Manuel da Costa Ataíde (Lopes, 1942).

Em 2012, ao final da disciplina "Representações, Imaginário e Tecnologia", do PPG- FAU-USP-SP, como trabalho de conclusão, foram realizados alguns registros e descrições dos desenhos existentes na Capela com intuito de documentar o seu estado atual e "trazer aos olhos" as suas características, esse trabalho será chamado de "Proto-Documentação", nesse artigo. 


\section{Proto-Documentação}

A Proto-Documentação, citada anteriormente suscitou uma série de análises e indagações sobre a própria natureza dos desenhos e sobre os processos de registro e representação dos mesmos enquanto objeto de estudo, norteando novas Documentações. Essa primeira aproximação com o objeto de estudo se deu a partir de análise visual, descrição textual e registro fotográfico digital.

Sob a pintura clara observam-se algumas áreas avermelhadas como riscos de sanguínea borrados pela pintura, talvez posterior. Alguns trechos da parede são demasiadamente escurecidos numa coloração bege, criando um sombreado indefinido, parecendo acúmulo de poeira.

Os riscos apresentam variações de instrumentos: grafite seco cinza, carvão preto aparentemente oleoso, carvão preto seco e um ocre avermelhado grosso parecido com sanguínea.

Observam-se várias camadas de fundo sendo a última de um branco encardido acinzentado onde são visíveis marcas de pincel largo, como uma "brocha".

Existe um "quadriculado" em toda superfície, de um palmo aproximadamente, verticalmente, aonde o desenho aparentemente se estrutura.

Os riscos apresentam volutas, curvas e contracurvas além de elementos típicos da ornamentação de edifícios religiosos e interiores do período colonial.

Mescla em uma só sequência vista frontal e lateral daquilo que parece ser um altar alinhado com um retábulo. De uma vista lateral para a frontal as linhas seguem contínuas de maneira a preservar as proporções.

Na parte inferior nota-se o risco de um altar e há semelhança com os retábulos colaterais centrais da mesma capela, o que deve ser analisado em etapa posterior por semelhança.

Há trechos completos e detalhados e outros incompletos. Em muitos momentos tem-se a impressão da adoção de instrumentos auxiliares, dada à rigidez e precisão do risco. Em outros pontos a repetição de traços cria linhas "grossas" e "cabeludas", resultando em desenhos mais esquemáticos e "soltos".

A parede sofreu intervenções de manutenção em algumas rachaduras que encobriram parte do risco. A argamassa parece estufada em vários pontos, deixando visualmente a sensação de descolamento eminente.

A área em que se encontra o risco, por não receber manutenção adequada, apresenta muitas rachaduras que parecem ser da camada de revestimento, ou seja, na superfície de argamassa. Abaixo, o desenho mostra a sequência de rachaduras visíveis.

Os traços mais fortes ficam até a altura dos olhos e um pouco acima dos braços erguidos, apesar de haverem riscos cobertos por uma camada de tinta branca até a parte mais alta da parede.

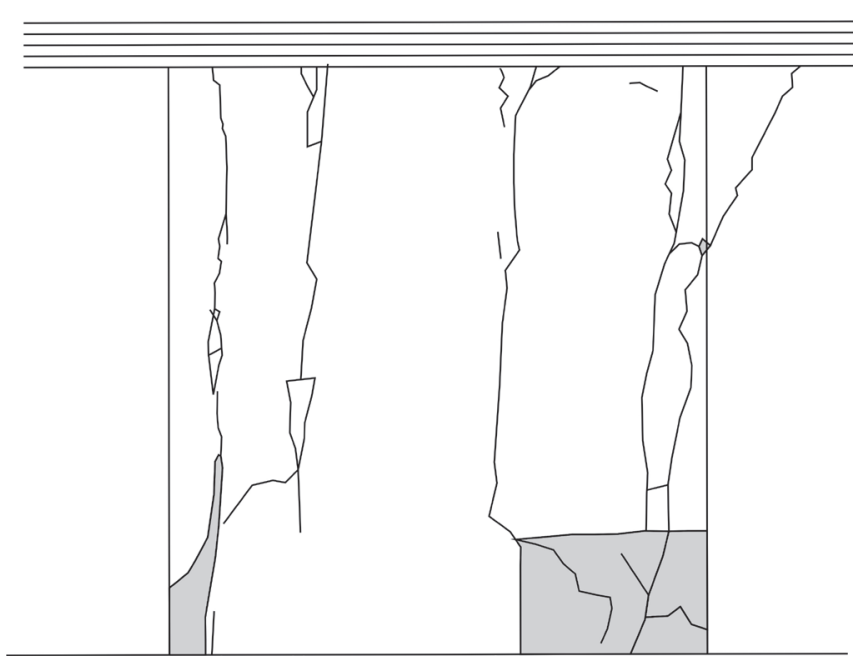

Figura 3: Desenho esquemático sem escala que indica os pontos mais críticos com rachaduras e intervenções de manutenção com cimento que encobrem parte dos desenhos na parede.

$\mathrm{Na}$ área mais acessível os desenhos são mais nítidos, com uma sequência de "reforços", inclusive com uso de materiais aparentemente distintos. Há áreas borradas como se houvesse sido esfregado (efeito tipo "esfuminho"), mas não aparentando fazer parte do processo de desenho como um acidente ou descuido.

Na área mais alta, de difícil acesso, existem traços menos visíveis, e com traçado mais uniforme, aparentemente com tantos detalhes quanto na área mais nítida. Por baixo dos riscos parece haver alguma pintura encoberta, com tons escuros, mas a não uniformidade da superfície cria sombras que se alternam dependendo da luminosidade do ambiente e do ponto de onde se posiciona, criando em alguns momentos a ilusão de desenhos figurativos, necessitando de análises mais aprofundadas.

A Proto-Documentação embasou análises posteriores, além de ter suscitado uma série de indagações sobre a própria natureza dos desenhos e sobre os processos de registro e representação dos mesmos enquanto objeto de estudo, norteando novas Documentações. Essa primeira aproximação com o objeto de estudo se deu a partir de análise visual, descrição textual e registro fotográfico digital. Em seguida iniciou-se um processo de vetorização computadorizada, dividido em duas linhas de experimentação:

1) apoiado no uso de softwares, porém manualmente, desenhando de maneira sobreposta os traços reconhecíveis nas imagens digitalizadas, a partir de análises visuais, permitindo uma reflexão sobre as características apreensíveis e formas identificáveis, e a criação de camadas organizadas por uma lógica própria desse processo reflexivo.

2) vetorização automatizada a partir de softwares, com intuito de verificar a capacidade de identificação de camadas e subcamadas de informação, a partir da lógica dos algoritmos e estruturas da composição: linhas, cores, limites, resolução, etc. 

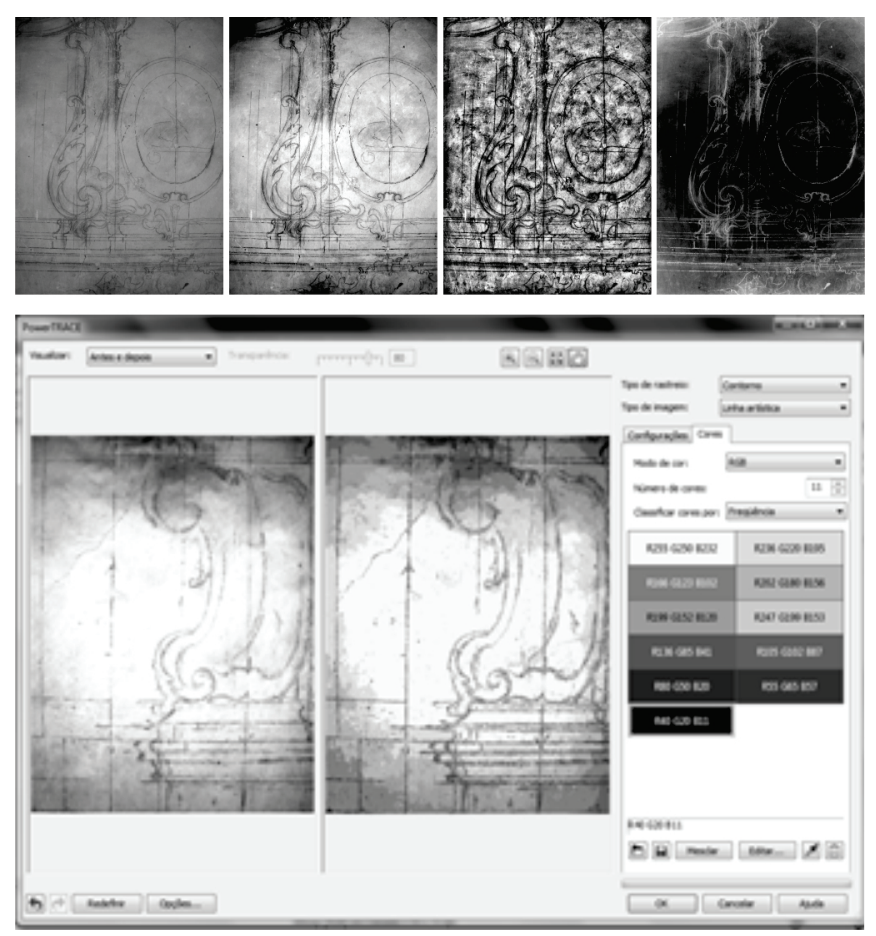

Figura 4: Parte do processo de manipulação dos registros fotográficos, com objetivo de digitalização do risco existente na Parede do Consistório da Capela do Carmo de Ouro Preto. Acima quatro exemplos de Equalização de camadas e Canais de cores, além de distorções tridimensionais, e na imagem maior o processo de Vetorização automatizada por algoritmos.

A partir da Proto-documentação que resultou em um mapeamento amplo a partir de fotografias, iniciou-se o processo de vetorização do desenho.

A vetorização manual apoiada no uso de softwares de desenho como os comerciais CorelDraw e Adobe llustrator ou o gratuito InksCape, exige um período de análise e reflexão. Cuja identificação do traçado é pautado na interpretação das imagens e anotações. Elementos que aparentemente seriam parte do desenho podem ser identificados como rachaduras em uma análise mais cuidadosa.

A utilização de recursos de manipulação das imagens ajuda ressaltar informações, como o simples ajuste de contrastes ou a divisão das cores por canais. Permitindo a verificação de elementos que passariam despercebidos.

Nos testes realizados de vetorização automatizada, a falta de interpretação do significado do desenho pelo software, gera muitas distorções da informação, agregando elementos distintos a partir de suas tonalidades ou canais.

Rapidamente constatou-se que a interpretação dessas informações, não pode se pautar puramente na estrutura formal e compositiva. Uma vez que se trata de registros vinculados a uma tradição histórica e tecnológica, cuja compreensão deve levar em conta os estudos acerca da história dos processos projetuais ou "projetação" no Brasil. Essa incursão pelo campo da História exige o cruzamento de informações teóricas, fatos e conceitos de maneira crítica e reflexiva, em que muitas vezes são pautadas em dados subjetivos, porém, que podem ser fundamentados. Isso quer dizer que se faz necessária aplicação de métodos científicos não ortodoxos para a compreensão desses documentos, como constata Birger Sevaldson (2002) em artigo sobre os processos científicos no campo do Design.

Pelo viés tecnológico, os desenhos estudados, revelam uma pequena parte dos procedimentos historicamente adotados desde o período colonial brasileiro para a concepção e fabricação da arquitetura. O que permite, por exemplo, uma reflexão sobre a revisão ou adequação de valores culturais arraigados em nossa sociedade e os procedimentos aplicados no uso das tecnologias emergentes.

A digitalização do desenho, está orientado pela necessidade de interpretação de sua estrutura compositiva, o que permite a verificação de dados históricos, como a comparação entre o risco e o retábulo. Estudo esse que pela bibliografia consultada ainda é inédito, carecendo de um aprofundamento, pois apenas comentário são feitos e pautados nas pesquisas de Francisco Antônio Lopes.

Em conversas informais com o professor Benedito Lima de Toledo, que ministrou aulas no curso "Cultura e Arte Barroca" pela Universidade Federal de Ouro Preto, este afirmou que em um exercício do curso "Cultura e Arte Barroca" chegou a fazer análises do Risco, mas esse material não foi localizado ainda, o que seria de grande valia, pois poderíamos estabelecer comparativos sobre o "estado da arte" em dois momentos distintos.

Em uma análise preliminar do desenho, comparado com o retábulo, podemos verificar uma semelhança estrutural, por conta das curvas e contracurvas que compõem a sua forma principal, porém, quando nos atemos aos detalhes, como as folhagens e rocalhas observamos uma grande variação entre ambos.

\section{Considerações Finais}

A criação de análises visuais permite a imersão nos detalhes do objeto de estudo, muitas vezes não apreensíveis in loco, mesmo pelo olhar mais atento. A partir da Proto-Documentação, foi feito um amplo registro fotográfico e descritivo e em seguida foram produzidos documentos visuais usando a Computação Gráfica, porém, constatou-se que a necessidade de reflexão a partir da observação influenciou esse processo, resultando em um processo de trabalho apoiado por recursos de manipulação de imagens, mas cujo resultado, depende exclusivamente da análise crítica.

Pela bibliografia consultada, trata-se de um trabalho inédito de documentação e análise de um objeto de inestimável valor histórico. Porém, há possibilidades de se encontrar registros feitos há algumas décadas pelo Professor Benedito Lima de Toledo, o que pode enriquecer as análises. 

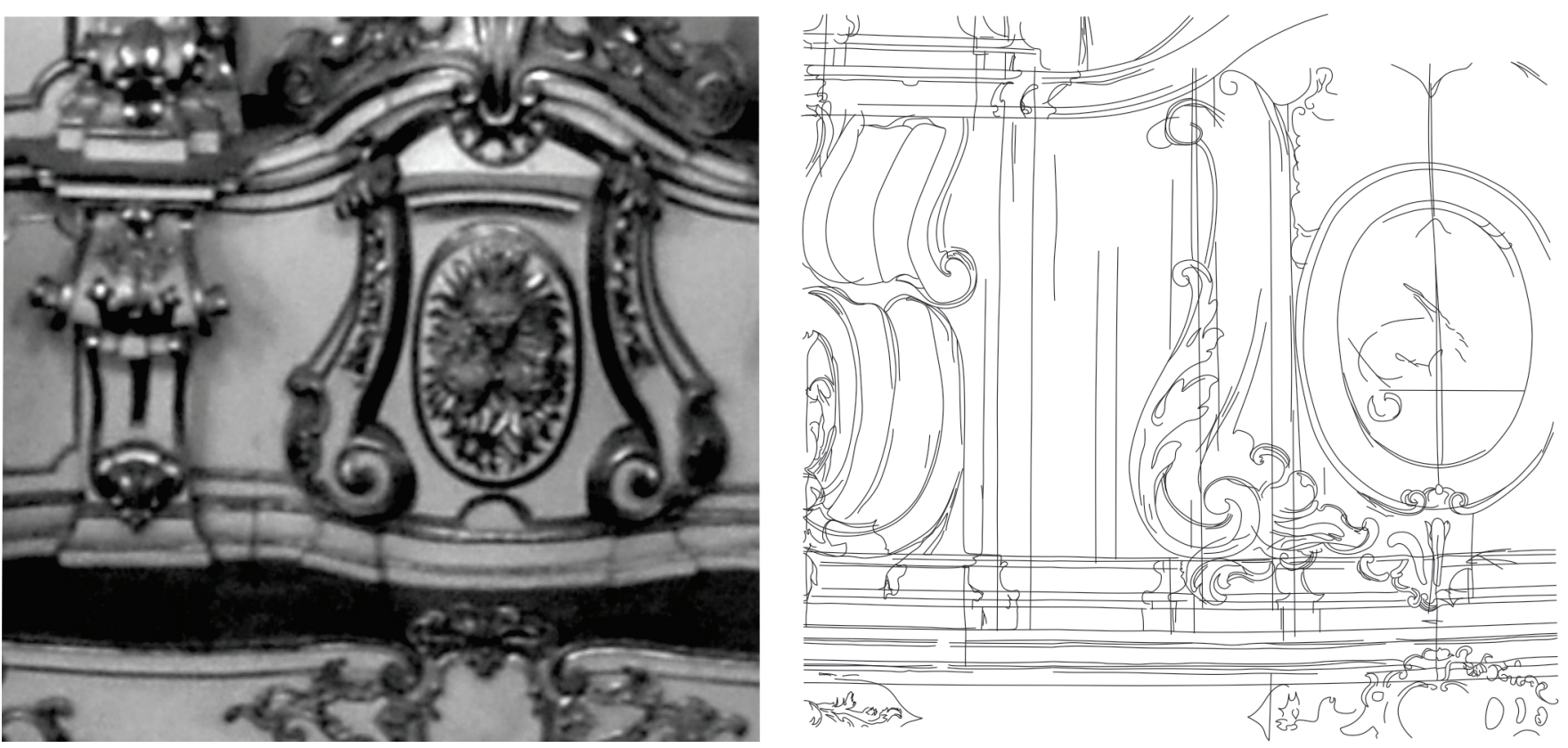

Figura 5: Comparação entre o Risco vetorizado manualmente e o retábulo (detalhe de foto de Lia Sipaúba).

A comparação desse Risco com o retábulo que é mencionado nos Autos da Irmandade do Carmo, demostra que há diferença na composição dos detalhes apesar da estrutura formal se manter apreensível. Isso pode ser interpretado como a sobreposição de engenhos e modos de fábrica, influenciados tanto pelos membros

\section{Agradecimentos}

Agradecimentos ao Núcleo de Apoio à Pesquisa em Ambientes Colaborativos - Na Web, pelo apoio. À Irmandade do Carmo de Ouro Preto, pela gentileza com que sempre são atendidos os pedidos de pesquisa no interior da Igreja. Ao Museu da Inconfidência, e pelos técnicos da Casa do Pilar, cujo apoio a pesquisa em documentos primários é sempre muito ágil. $E$ finalmente à pesquisadora e professora Lia Sipaúba, pela cessão de fotos para este estudo.

\section{Referências}

Bluteau, R. (1728). BRASILIANA USP. [Online]. [Citado em: 01 de 09 de 2013.] http://www.brasiliana.usp.br/dicionario/edicao/1.

Bury, J. (2006). Arquitetura e Arte no Brasil Colonial. Brasília, DF: IPHAN / MONUMENTA.

Lopes, F. A. (1942). História da Construção da construção da igreja do Carmo de Ouro Preto. Rio de Janeiro, RJ: Ministério da Educação e Saúde.

Neves, M. A. \& Cotta, A. C. (2012) Do Monte Carmelo a Vila Rica: Aspectos Históricos da Ordem Terceira e da Igreja do Carmo de Ouro Preto. Ouro Preto, MG: Edição da Autora.

Sevaldson, B. (2002). The integrated conglomerate approach: A suggestion for a generic model of design research. In Durling \& Friedman (eds). Foundations for the Future Doctoral Education in Design. La Clusaz France, 8-12 July, 2000. Staffortshire University. 163-170. 